\title{
Silencing of CDC20 suppresses metastatic castration-resistant prostate cancer growth and enhances chemosensitivity to docetaxel
}

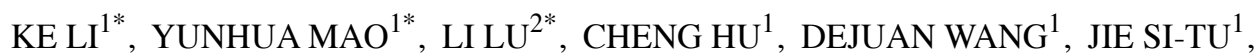 \\ MINHUA LU ${ }^{1}$, SHUBIN PENG ${ }^{1}$, JIANGUANG QIU ${ }^{1}$ and XIN GAO ${ }^{1}$ \\ ${ }^{1}$ Department of Urology, The Third Affiliated Hospital, Sun Yat-sen University; ${ }^{2}$ Department of Urology, \\ The Sixth Affiliated Hospital, Sun Yat-sen University, Guangzhou, Guangdong, P.R. China
}

Received June 5, 2016; Accepted July 26, 2016

DOI: $10.3892 /$ ijo.2016.3671

\begin{abstract}
The role of cell division cycle 20 (CDC20) was investigated in chemoresistance to decetaxel and the underlying mechanisms in metastatic castration-resistant prostate cancer (mCRPC). MTT assays were performed to determine effects of siRNA-mediated CDC20 knockdown on cell proliferation and anticancer activity of docetaxel. Western blot analyses were conducted to detect changes of Akt and Wnt signaling. Furthermore, in vivo growth of $\mathrm{PCa}$ was examined in nude mice treated with siCDC20 or docetaxel alone or in combination. CDC20 was overexpressed in mCRPC cells. Knockdown of CDC20 suppressed cell proliferation and enhanced anticancer effect of docetaxel with $\mathrm{IC}_{50}$ reducing from 0.358 to $0.188 \mu \mathrm{g} / \mathrm{ml}$ in PC3 cells and 0.307 to $0.162 \mu \mathrm{g} /$ $\mathrm{ml}$ in DU145 cells $(\mathrm{P}<0.01)$. While no change of Akt signaling was observed, inhibition of Wnt/ $\beta$-catenin signaling was detected upon CDC20 silencing. Xenograft tumor growth was significantly reduced in nude mice by CDC20 inhibition. The additional treatment of siCDC20 achieved better anticancer effects than that of docetaxel alone. Silencing of CDC20 may be a new strategy to improve chemosensitization to docetaxel in $\mathrm{mCRPC}$.
\end{abstract}

\section{Introduction}

Prostate cancer (PCa) remains the most commonly diagnosed malignancy and the second leading cause of cancer-related deaths among men in Europe and the United States $(1,2)$.

Correspondence to: Dr Xin Gao or Dr Jianguang Qiu, Department of Urology, The Third Affiliated Hospital of Sun Yat-Sen University, Guangzhou, Guangdong 510630, P.R. China

E-mail: gaoxinmw@sina.com

E-mail: qjg702@qq.com

*Contributed equally

Key words: prostatic neoplasms, cell division cycle 20, chemotherapy
Despite recent therapeutic advances, most PCa cases inevitably progress to the advanced stage, castration-resistant prostate cancer (CRPC). In this setting, docetaxel-based chemotherapy is the mainstay of treatment. The majority of patients achieve an overall survival benefit, but the duration of benefit is limited and many patients eventually develop resistance $(3,4)$. Thus, the identification of biomolecules involving in chemoresistance may improve treatment strategies in the clinical practice.

The mechanism of antimitotic drugs including docetaxel is to perturb mitotic spindle assembly, which activates the spindle assembly checkpoint (SAC). SAC induces mitotic arrest and subsequently tumor cells either die in mitosis or exit mitosis by slippage into the next phase. Cells that resist killing by premature exit show decreased sensitivity to spindleperturbing drugs (5-8), indicating premature mitotic exit might render chemoresistance to cancer cells. CDC20 (cell division cycle 20) was first discovered in budding yeast in 1973 (9). As a critical gene for cell cycle progression, it activates the anaphase-promoting complex/cyclosome (APC/C), thus promoting mitotic exit through ubiquitin-dependent proteasomal degradation of proteins such as securin and cyclin B1 $(10,11)$. Overexpression of CDC20 have been reported to be associated with unfavorable pathologic features and poor prognosis in various types of cancers (12). Elegant studies also revealed that knockdown of CDC20 efficiently killed slippageprone cancer cells, suggesting an inhibitory role of CDC20 knockdown in the survival of cancer cells $(13,14)$. However, its potential role and possible mechanisms in chemoresistance of $\mathrm{PCa}$ remains largely elusive.

Previously, we demonstrated that CDC20 overexpression in PCa was correlated with higher risk of biochemical recurrence (15). In this study, we found CDC20 was increased in mCRPC cell lines and siRNA-mediated knockdown of CDC20 remarkably inhibited proliferation of mCRPC cells. Interestingly, silencing of CDC20 enhanced chemosensitivity to doxetaxel in mCRPC cells through inhibition of $\mathrm{Wnt} / \beta$ catenin signaling. In the xenograft models, we observed intratumor injection of siRNA against CDC20 significantly reduced tumor growth and augmented chemotherapeutic effect of docetaxel. 


\section{Materials and methods}

Cell lines and culture conditions. Human immortalized normal prostate epithelial cell line RWPE-1 and prostate cancer cell lines 22RV1, PC3, DU145, LNCaP were purchased from the American Type Culture Collection (ATCC, Rockville, MD, USA), and PC3M was obtained from Medical Research Center of the Third Affiliated Hospital. PCa cells were cultured in Roswell Park Memorial Institute (RPMI) medium 1640 (Gibco, CA, USA) supplemented with $10 \%$ fetal bovine serum (FBS). RWPE-1 cells were cultured in keratinocyte serum-free medium (Gibco). All cell lines were maintained in a humidified incubator at $5 \% \mathrm{CO}_{2}$ and $37^{\circ} \mathrm{C}$.

Quantitative reverse transcription-polymerase chain reaction. Total RNA isolation was performed using TRIzol (Invitrogen, NY, USA) according to the manufacturer's instructions. RNA concentration and purity ratios (OD260/280, OD260/230) were measured with NanoDrop 1000 spectrophotometer (Thermo Fisher Scientific Inc., Waltham, USA). Total RNA $(1.0 \mu \mathrm{g})$ was reverse transcribed into cDNA with the Transcriptor First Strand cDNA Synthesis kit (Roche, Mannheim, Germany). Quantitiative real-time polymerase chain reaction (qRT-PCR) analysis were carried out in triplicate using SYBR Green I Master kit (Roche) on LightCycler ${ }^{\circledR} 480$ System (Roche). A human GAPDH gene was used as an endogenous control for sample normalization. PCR primers for CDC20 were as previously reported (16). Results are presented as the ratio relative to GAPDH.

Western blot analysis. Cells were washed twice with precold phosphate-buffered saline (PBS) and proteins were extracted using RIPA (Cell Signaling Technology, Danvers, MA, USA) containing protease inhibitor and phosphatase inhibitor. Protein concentration was measured by Bradford method. Equal amounts of protein were resolved on $10 \%$ SDS-PAGE gels and transferred to polyvinylidene difluoride (PVDF) membranes. The membranes were blocked in $5 \%$ milk for $1 \mathrm{~h}$ and incubated overnight at $4{ }^{\circ} \mathrm{C}$ with indicated primary antibodies: CDC20 (1:2,000, ABClone), total Akt (1:1,000, Cell Signaling Technology), phospho-Akt (Ser473) (1:1,000, Cell Signaling Technology), active $\beta$-catenin $(1: 1,000$, Cell Signaling Technology), phospho- $\beta$-catenin (Ser33/37/Thr41) (1:1,000, Cell Signaling Technology) and GAPDH (1:2,000, Cell Signaling Technology). Secondary antibodies were used to detect the primary antibodies. Protein bands were visualized using FluorChem M (ProteinSimple, CA, USA).

SiRNA transfection. Human siRNA oligos were purchased from Invitrogen. Human siRNA were transfected into subconfluent cells with Lipofectamine ${ }^{\mathrm{TM}}$ RNAiMAX (Invitrogen) in accordance with the manufacturer's instructions.

Cell proliferation/viability assay. Cells were seeded into 96-well plates at a density of $5 \times 10^{3}$ per well, MTT assay was used to read the absorbance of $490 \mathrm{~nm}$ at selected time-points. In addition, treatment effects of docetaxel on cell proliferation was also examined; that is, after the adhesion culture media were replaced with that containing indicated concentration of docetaxel and MTT assays were performed at $48 \mathrm{~h}$ post- seeding. Each experiment was performed in triplicate and cell proliferation is expressed as fold change \pm SEM compared to values obtained on the first day of culturing. The average half maximal inhibitory concentrations $\left(\mathrm{IC}_{50}\right)$ were calculated using Graphpad Prism 5.0 software.

In vivo xenograft model of human CRPC. The animal experiments were approved by the Institutional Animal Care and Use Committee at Sun Yat-Sen University and performed according to its guidelines. PC3 and DU145 cells $\left(3 \times 10^{6}\right.$ cells per mouse) were subcutaneously injected into the flank region of 5-week-old male BALB/c nude mice. Tumor size was measured every 3 days by handheld caliper and tumor volume was calculated as follows: tumor volume $\left(\mathrm{mm}^{3}\right)=$ length $\mathrm{x}$ width $^{2} \times 0.52$. When the tumor volume reached $100 \mathrm{~mm}^{3}$, the mice were divided randomly into 4 groups ( $n=6$ for each group) and tumor volumes between groups were not statistically significant. siRNA $(10 \mu \mathrm{M} \times 50 \mu \mathrm{l})$ was injected into the tumor once a week. Docetaxel (10 mg/kg body weight) was administered by intraperitoneal injection every week. Thereafter, tumor volumes were measured every 7 days. After 5 weeks of treatment, mice were sacrificed and primary tumors were excised, weighed, and captured.

Statistical analysis. Statistical analyses were performed using SPSS 17.0 (SPSS Inc., USA). Results were presented as means \pm SEM of three independent experiments conducted at least in triplicate. Two-tailed Student's t-test was used to compare results between groups. $\mathrm{P}<0.05$ was considered statistically significant.

\section{Results}

CDC20 expression is increased in mCRPC cell lines. To investigate the potential role of CDC20 in PCa cells, we performed RT-PCR and western blotting to determine the levels of CDC20 mRNA and protein in normal epithelial cell line of prostate RWPE-1 and several PCa cell lines, including primary PCa cell line (22RV1), mCRPC cell lines (PC3, PC3M, DU145) and metastatic hormone-sensitive cell line (LNCaP). As shown in Fig. 1, although CDC20 was modestly expressed in RWPE-1, it was remarkably increased in mCRPC cell lines both at mRNA and protein levels. PC3 and DU145 were chosen for further investigation.

Silencing of CDC20 suppresses cell proliferation of $m C R P C$ cells. In order to determine the effect of CDC20 on proliferation of CRPC cells, siRNA against CDC20 was transfected into PC3 and DU145 cells. As determined by western blot analysis, endogenous expression of CDC20 was significantly reduced by the two siRNA, especially the siRNA-1 (Fig. 2A and B). The MTT assays showed that knockdown of CDC20 remarkably suppressed proliferation of mCRPC cells in comparison with the control group (Fig. 2C and D), indicating CDC20 promotes proliferation of $\mathrm{mCRPC}$.

Inhibition of CDC20 augments chemosensitivity to docetaxel in $m C R P C$ cells through Wnt/ $\beta$-catenin signaling. To further investigate the possible role of CDC20 in regulating chemosensitivity of CRPC cells, cells were transfected with siRNA 
A

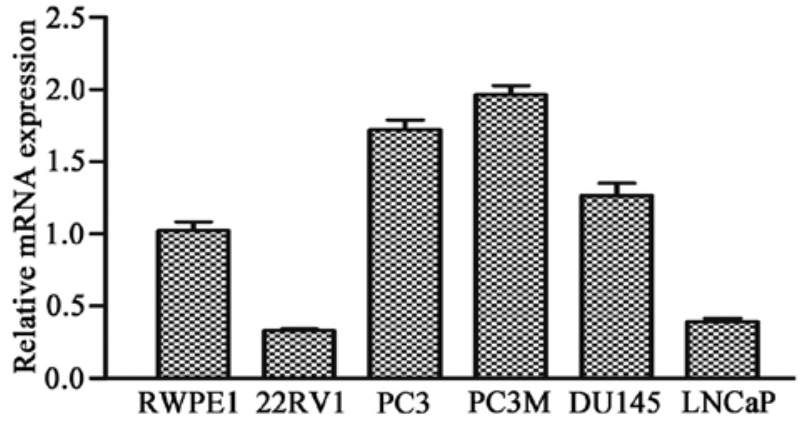

B

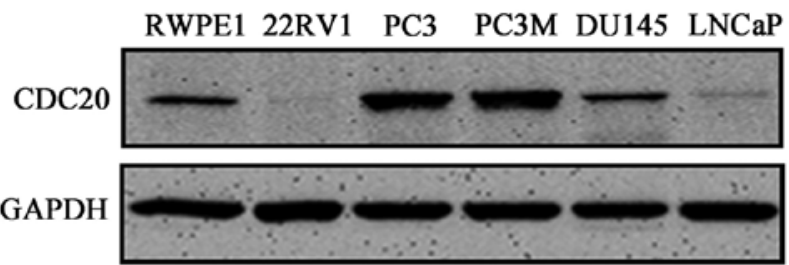

Figure 1. CDC20 expression levels in immortalized epithelial cell line and prostate cancer cell lines. (A) Relative mRNA expression of CDC20 determined by qRT-PCR. Data are expressed as the mean \pm SEM. (B) Protein expression of $\mathrm{CDC} 20$ determined by western blotting.

and then treated with a mock agent or docetaxel of indicated concentration for another $48 \mathrm{~h}$. After silencing of CDC20, the $\mathrm{IC}_{50}$ of docetaxel was significantly reduced from 0.358 to $0.188 \mu \mathrm{g} / \mathrm{ml}(\mathrm{P}<0.01)$ in $\mathrm{PC} 3$ cells and 0.307 to $0.162 \mu \mathrm{g} /$ $\mathrm{ml}(\mathrm{P}<0.01)$ in DU145 cells (Fig. 3A and B). To clarify the mechanisms of action, we detected the effect of CDC20 silencing on Akt signaling and $\mathrm{Wnt} / \beta$-catenin signaling because of their reported involvement in cancer chemoresistance. No changes were observed in the expression levels of phospho-Akt and total Akt protein. However, phospho- $\beta$ - catenin on Ser33/37/Thr41 residues (inactivated $\beta$-catenin) was increased and total $\beta$-catenin was decreased, indicating Wnt $/ \beta$-catenin signaling was inhibited upon CDC20 inhibition. These results indicate that inhibition of CDC20 augmented chemosensitivity to docetaxel in mCRPC cells, which is achieved partly through inhibiting Wnt/ $\beta$-catenin signaling (Fig. 3C-F).

Silencing of CDC2O reduces tumor growth and enhances chemotherapeutic effect of docetaxel in CRPC xenografts. To validate the research results in vitro, we performed in vivo studies in nude mice. The tumor growth curves are shown in Fig. 4A and B. Consistent with the results of in vitro studies, silencing of CDC20 significantly reduced tumor growth at different time-points, showing better anticancer effect than docetaxel. In addition, the average weights of harvested tumors in groups treated with control saline, siCDC20, docetaxel and a combination of siCDC20 and docetaxel were $1148.5 \pm 168.0$, $801.3 \pm 50.8,579.2 \pm 98.4,258.6 \pm 103.7 \mathrm{mg}$ for PC3 tumors and $972.3 \pm 100.1,767.5 \pm 79.4,541.8 \pm 118.1,171.8 \pm 80.1 \mathrm{mg}$ for DU145 tumors respectively $(\mathrm{P}<0.001$ compared with the control) (Fig. 4C and D).

\section{Discussion}

Prostate cancer ( $\mathrm{PCa}$ ) is initially responsive to androgen deprivation therapy. Unfortunately, many patients eventually become resistant and progress to metastatic castration-resistant prostate cancer (mCRPC), which is an incurable and aggressive phenotype. For several years, docetaxel chemotherapy has been the primary standard of care for patients with mCRPC, though it prolongs survival only a limited time (17). PCa is a highly heterogeneous disease (18). It is likely that some cancer cells are intrinsically resistant to docetaxel and some
A
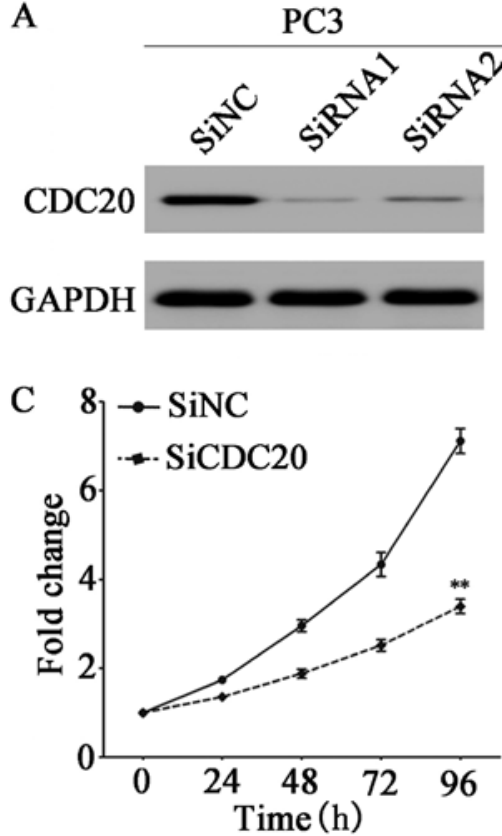

B
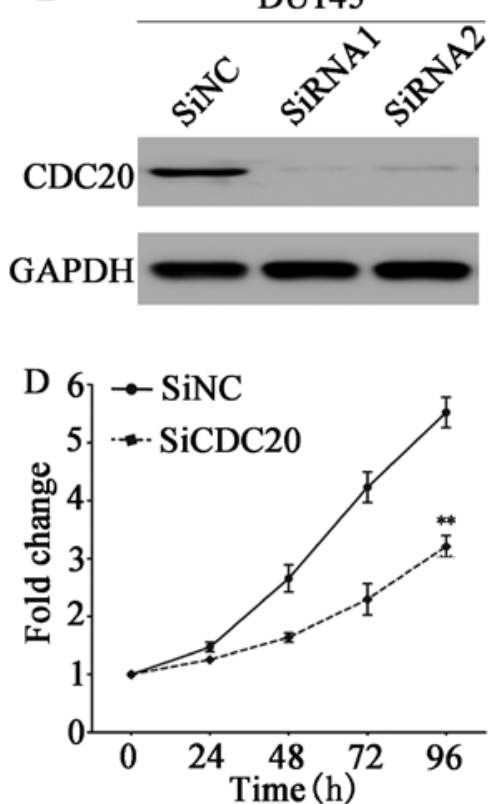

Figure 2. Knockdown of CDC20 suppressed proliferation of mCRPC cells. CDC20 protein expression in PC3 cells (A) and DU145 cells (B) was significantly inhibited by siRNA. MTT assays showed knockdown of CDC20 remarkably suppressed proliferation of PC3 (C) and DU145 cells (D). Data are expressed as fold change \pm SEM compared to the absorbance at OD490 nm on the first day, ${ }^{* * *} \mathrm{P}<0.001$ using Student's t-test. 
A

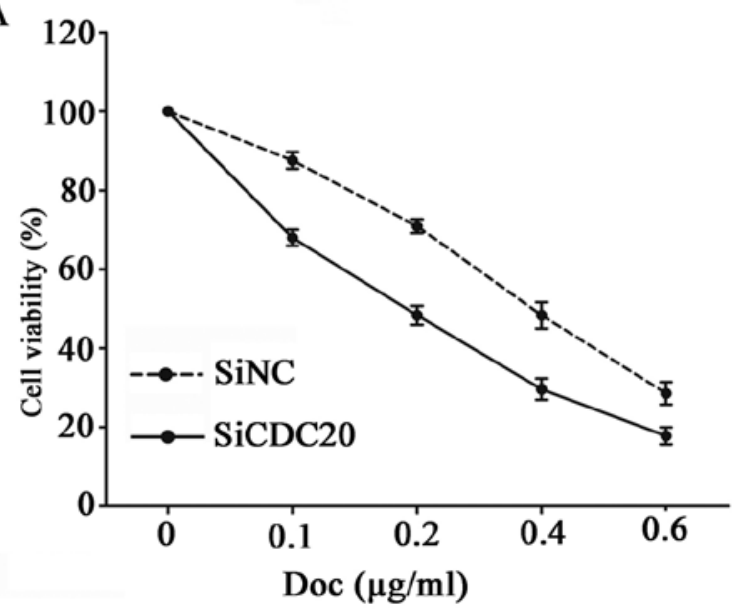

C



B

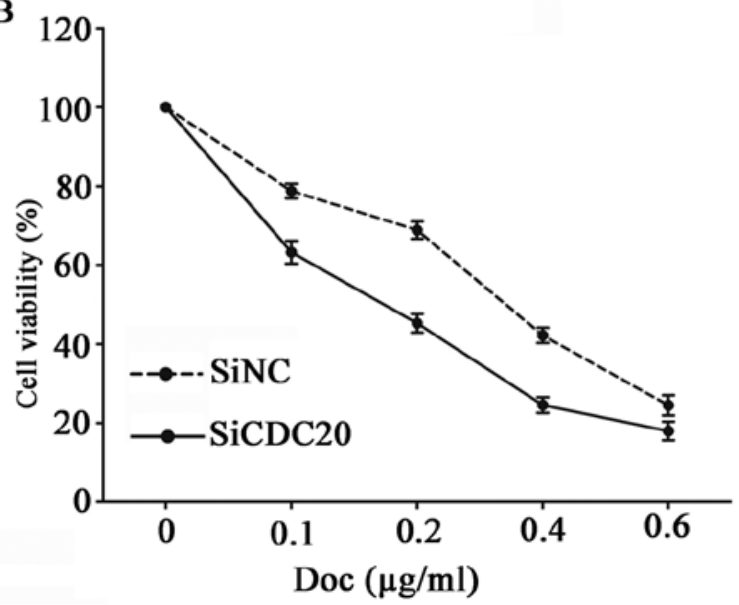

D

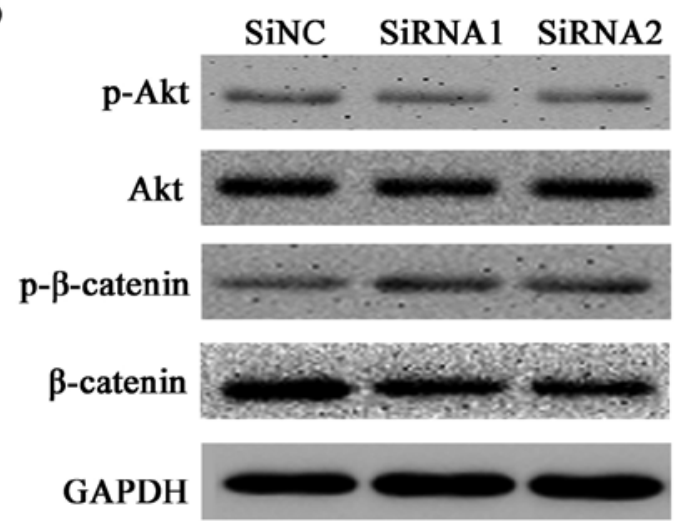

F

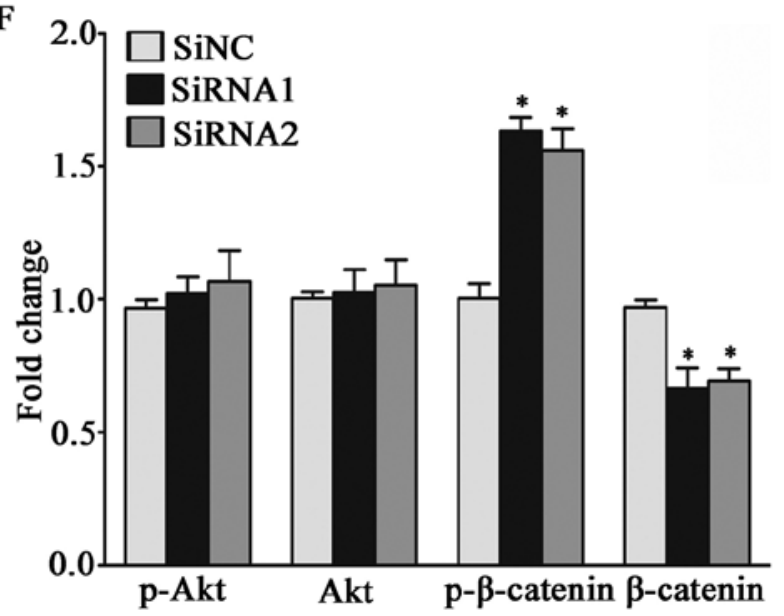

Figure 3. Inhibition of CDC20 augments chemosensitivity to docetaxel in mCRPC cells through inhibiting Wnt/ $\beta$-catenin signaling. Inhibition of CDC20 enhanced anticancer effect of docetaxel in PC3 (A) and DU145 cells (B). Knockdown of CDC20 inhibited Wnt/ $\beta$-catenin signaling whereas it did not change the Akt pathway. Western blot analysis of expression changes of Akt and Wnt/ $\beta$-catenin signaling in PC3 (C) and DU145 (D) cells. Protein expression levels in PC3 (E) and DU145 (F) cells were standardized by GAPDH and presented as fold change \pm SEM compared to the control group. Cells were treated with non-targeted siRNA (SiNC), siRNAs targeting CDC20 (SiRNA1 and SiRNA2). All experiments were performed three times independently, ${ }^{*}$ P 0.05 using Student's t-test.

other cancer cells acquire resistance during the chemotherapy. Therefore, resensitizing PCa to docetaxel has been a great challenge and is of critical significance for improving treatment strategies.

Cell division cycle 20 (CDC20), is a WD40 repeat domaincontaining E3 ligase that associates with and activates the anaphase-promoting complex (APC). APC ${ }^{\mathrm{CDC} 20}$ recognizes the D-box or KEN box of substrates to promote proteasomal degradation of securin and cyclin $\mathrm{B}$, triggering transition from metaphase to anaphase and mitotic exit (19). It has been reported that multiple cancer types showed increased CDC20 expression and its expression level correlated with clinico- 
A

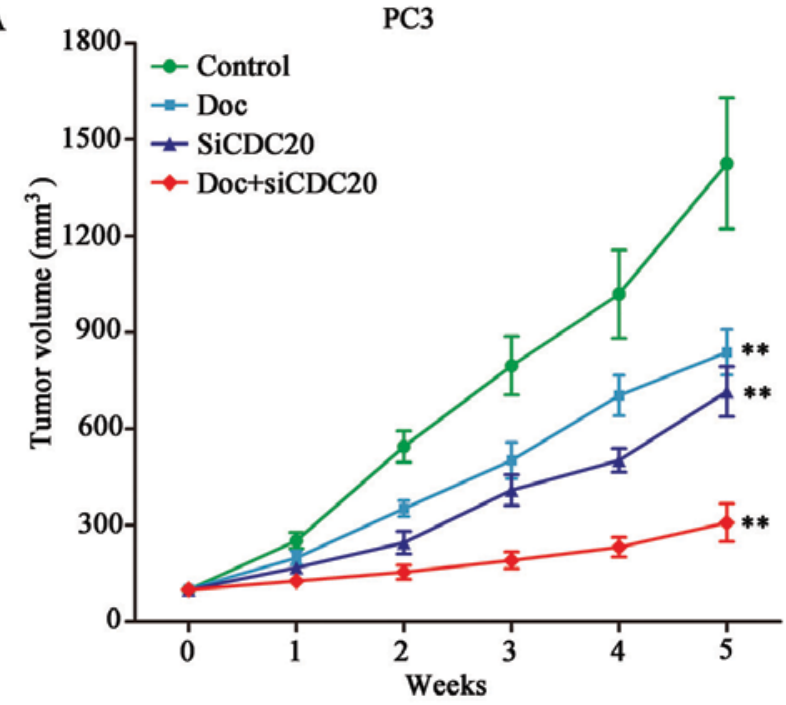

C
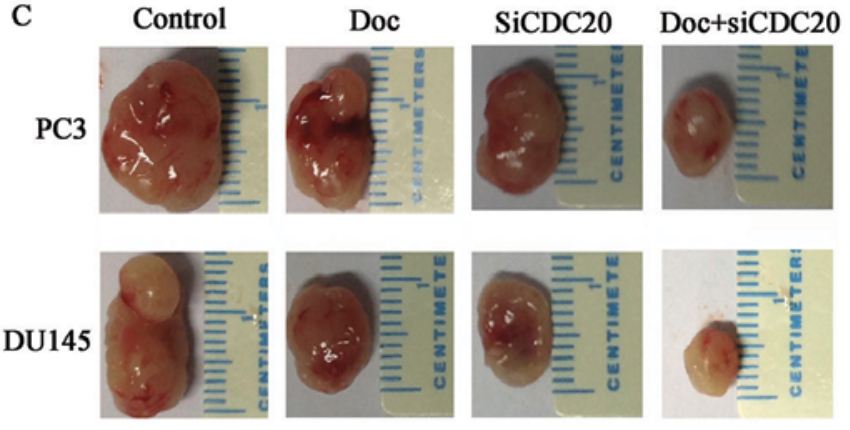

B

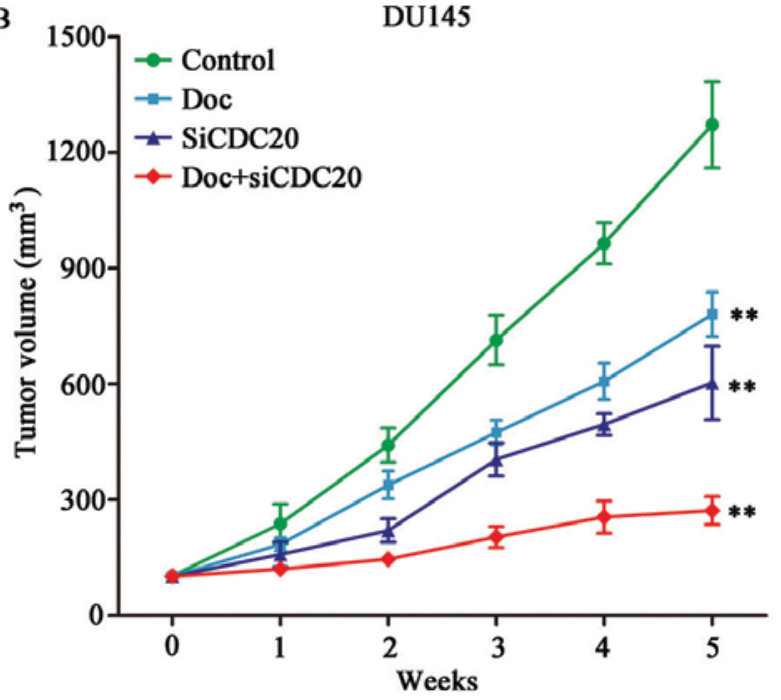

D

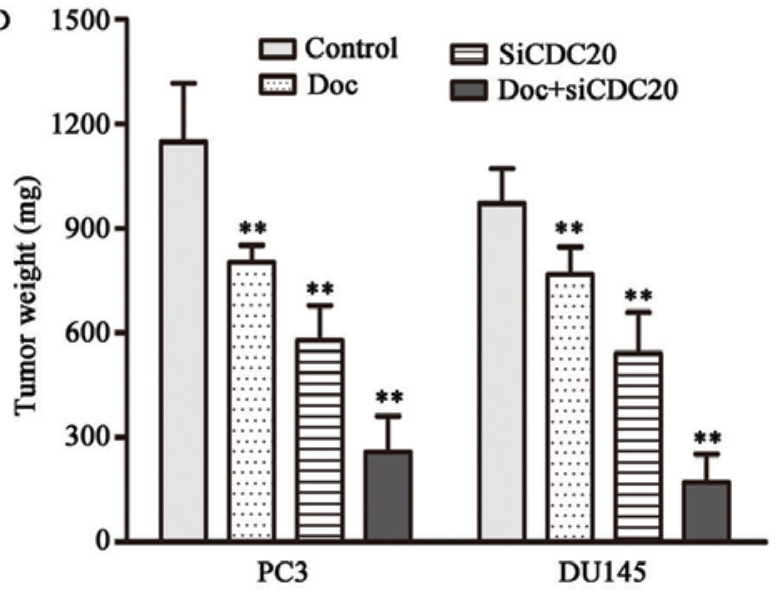

Figure 4. Effects of siRNA against CDC20 and docetaxel on xenograft tumor growth. Tumor growth curves of PC3 (A) and DU145 (B) cells in mice treated with indicated treatments ( $\mathrm{n}=6$ for each group). (C) Representative images of harvested tumors after 5 weeks of treatments. (D) Average weight of harvested tumors in each group. Control, intraperitoneal injection of saline. Doc, intraperitoneal injection of docetaxel (10 mg/ $\mathrm{kg}$ body weight). siCDC20, intratumoral injection of siRNA against CDC20 $(10 \mu \mathrm{M} \times 50 \mu \mathrm{l})$. Data are presented as mean \pm SEM. ${ }^{* *} \mathrm{P}<0.001$ compared with control group using Student's t-test.

pathological characteristics as well as prognosis $(20,21)$. In $\mathrm{PCa}$, we previously demonstrated high expression level of CDC20 associated with higher Gleason scores and predicted biochemical recurrence (15). Yet, there is no direct evidence on the role of CDC20 in chemotherapy of PCa.

In this study, we observed modest expression of CDC20 in normal epithelial cell line of prostate RWPE-1, which might be explained by the essential role of CDC20 for cell cycle progression in both normal and cancerous cells $(13,19)$. We also revealed that CDC20 was upregulated in $\mathrm{mCRPC}$ cell lines, representing an oncogenic role of CDC20 in PCa. Further, we demonstrated that inhibition of CDC20 achieved better antitumor effect than docetaxel, in agreement with the previous proposal that blocking mitotic exit was a better cancer therapeutic strategy than other cell cycle processes $(14,22)$. Silencing of CDC20 enhanced chemosensitivity to docetaxel both in vitro and in vivo, indicating CDC20 is a potential therapeutic target. In concert with our finding, depleting endogenous CDC20 induced chemosensitization in head and neck cancer cells (23). Indeed, inhibitors of CDC20 have provided a therapeutic window in a variety of cancers. Zeng et al reported that TAME (tosyl-L-arginine methyl ester), a small molecule, reduced CDC20 association with APC and resultantly suppressed APC activation $(24,25)$. Another small molecule, apcin, has recently been validated to bind CDC20 to prevent substrate recognition, thus competitively inhibiting the ubiquitination of CDC20 substrates (26). Other biocompounds such as Withaferin A, NAHA, ganodermanontriol (GDNT) and BCHHD leads to decreased CDC20 expression to exert anticancer activity (27-30). Based on our study, we propose that a combination of microtubuletargeting agents with inhibitors of mitotic exit could be much more effective than treatment using a single anticancer agent.

Mechanistically, we explored the changes of Akt and Wnt pathways upon CDC20 knockdown, because Akt and Wnt pathway have been reported to be implicated in protecting tumor cells against chemotherapeutic drugs $(31,32)$. Surprisingly, we identified depression of $\mathrm{Wnt} / \beta$ catenin signaling and no change of Akt pathway, suggesting CDC20 silencing achieved antitumor effect in PCa via inhibition of $\mathrm{Wnt} / \beta$-catenin signaling rather than Akt signaling. Consistently, an elegant study proposed that knockdown of 
CDC20 blocked Wnt signaling (33). Several studies have provided explanations for this finding. Firstly, Wnt/ $\beta$-catenin signaling has been discovered to be highly activated in prostate cancer stem cells (CSCs) (34). Secondly, CSCs have been proven to be key players associated with chemoresistance in PCa (35). Thirdly, it was documented that $\beta$-catenin directly interacted with the activation function 2 region (AF2) of the ligand binding domain of androgen receptor $(36,37)$, which was considered the critical role in PCa development, progression and chemoresistance. Furthermore, activation of $\beta$-catenin increased the membrane located efflux pump $\mathrm{P}$-glycoprotein(P-gp) expression, resulting in an active efflux of anticancer agents from cells and thus inducing multidrug resistance (38-40).

In conclusion, this study presents the preliminary evidence that $\mathrm{CDC} 20$ is significantly involved in mediating chemoresistance to docetaxel partly through inhibiting Wnt/ $\beta$ catenin signaling. Therefore, treatment strategies directed toward silencing CDC20 may improve chemosensitization to docetaxel in mCRPC.

\section{Acknowledgements}

This study was supported by National Natural Science Foundation of China $(81372728,81572503,81402111)$ and Medical Scientific Research Foundation of Guangdong Province (B2014140).

\section{References}

1. Siegel RL, Miller KD and Jemal A: Cancer statistics, 2016. CA Cancer J Clin 66: 7-30, 2016.

2. Torre LA, Bray F, Siegel RL, Ferlay J, Lortet-Tieulent J and Jemal A: Global cancer statistics, 2012. CA Cancer J Clin 65: 87-108, 2015.

3. Singh P, Yam M, Russell PJ and Khatri A: Molecular and traditional chemotherapy: A united front against prostate cancer. Cancer Lett 293: 1-14, 2010.

4. Seruga B, Ocana A and Tannock IF: Drug resistance in metastatic castration-resistant prostate cancer. Nat Rev Clin Oncol 8: 12-23, 2011.

5. Tao W, South VJ, Zhang Y, Davide JP, Farrell L, Kohl NE, Sepp-Lorenzino L and Lobell RB: Induction of apoptosis by an inhibitor of the mitotic kinesin KSP requires both activation of the spindle assembly checkpoint and mitotic slippage. Cancer Cell 8: 49-59, 2005

6. Swanton C, Marani M, Pardo O, Warne PH, Kelly G, Sahai E, Elustondo F, Chang J, Temple J, Ahmed AA, et al: Regulators of mitotic arrest and ceramide metabolism are determinants of sensitivity to paclitaxel and other chemotherapeutic drugs. Cancer Cell 11: 498-512, 2007.

7. Gascoigne KE and Taylor SS: Cancer cells display profound intra- and interline variation following prolonged exposure to antimitotic drugs. Cancer Cell 14: 111-122, 2008.

8. Bekier ME, Fischbach R, Lee J and Taylor WR: Length of mitotic arrest induced by microtubule-stabilizing drugs determines cell death after mitotic exit. Mol Cancer Ther 8: 1646-1654, 2009.

9. Hartwell LH, Mortimer RK, Culotti J and Culotti M: Genetic control of the cell division cycle in yeast: V. Genetic analysis of cdc mutants. Genetics 74: 267-286, 1973.

10. Primorac I and Musacchio A: Panta rhei: The APC/C at steady state. J Cell Biol 201: 177-189, 2013.

11. Pines J: Cubism and the cell cycle: The many faces of the APC/C Nat Rev Mol Cell Biol 12: 427-438, 2011.

12. Gayyed MF, El-Maqsoud NM, Tawfiek ER, El Gelany SA and Rahman MF: A comprehensive analysis of CDC20 overexpression in common malignant tumors from multiple organs: Its correlation with tumor grade and stage. Tumour Biol 37: 749-762, 2016.
13. Schlabach MR, Luo J, Solimini NL, Hu G, Xu Q, Li MZ, Zhao Z, Smogorzewska A, Sowa ME, Ang XL, et al: Cancer proliferation gene discovery through functional genomics. Science 319: 620-624, 2008.

14. Huang HC, Shi J, Orth JD and Mitchison TJ: Evidence that mitotic exit is a better cancer therapeutic target than spindle assembly. Cancer Cell 16: 347-358, 2009.

15. Mao Y, Li K, Lu L, Si-Tu J, Lu M and Gao X: Overexpression of Cdc20 in clinically localized prostate cancer: Relation to high Gleason score and biochemical recurrence after laparoscopic radical prostatectomy. Cancer Biomark 16: 351-358, 2016.

16. Li J, Gao JZ, Du JL, Huang ZX and Wei LX: Increased CDC20 expression is associated with development and progression of hepatocellular carcinoma. Int J Oncol 45: 1547-1555, 2014.

17. Tannock IF, de Wit R, Berry WR, Horti J, Pluzanska A, Chi KN, Oudard S, Théodore C, James ND, Turesson I, et al; TAX 327 Investigators: Docetaxel plus prednisone or mitoxantrone plus prednisone for advanced prostate cancer. N Engl J Med 351: 1502-1512, 2004

18. Mackinnon AC, Yan BC, Joseph LJ and Al-Ahmadie HA: Molecular biology underlying the clinical heterogeneity of prostate cancer: An update. Arch Pathol Lab Med 133: 1033-1040, 2009.

19. Yu H: Cdc20: A WD40 activator for a cell cycle degradation machine. Mol Cell 27: 3-16, 2007.

20. Wang L, Zhang J, Wan L, Zhou X, Wang Z and Wei W: Targeting $\mathrm{Cdc} 20$ as a novel cancer therapeutic strategy. Pharmacol Ther 151: 141-151, 2015

21. Wang Z, Wan L, Zhong J, Inuzuka H, Liu P, Sarkar FH and Wei W: Cdc20: A potential novel therapeutic target for cancer treatment. Curr Pharm Des 19: 3210-3214, 2013.

22. Manchado E, Guillamot M, de Cárcer G, Eguren M, Trickey M, García-Higuera I, Moreno S, Yamano H, Cañamero $M$ and Malumbres M: Targeting mitotic exit leads to tumor regression in vivo: Modulation by Cdk1, Mastl, and the PP2A/B55 $\alpha, \delta$ phosphatase. Cancer Cell 18: 641-654, 2010.

23. Wan L, Tan M, Yang J, Inuzuka H, Dai X, Wu T, Liu J, Shaik S, Chen G, Deng J, et al: APC(Cdc20) suppresses apoptosis through targeting Bim for ubiquitination and destruction. Dev Cell 29: 377-391, 2014.

24. Zeng X, Sigoillot F, Gaur S, Choi S, Pfaff KL, Oh DC, Hathaway N, Dimova N, Cuny GD and King RW: Pharmacologic inhibition of the anaphase-promoting complex induces a spindle checkpoint-dependent mitotic arrest in the absence of spindle damage. Cancer Cell 18: 382-395, 2010.

25. Zeng X and King RW: An APC/C inhibitor stabilizes cyclin B1 by prematurely terminating ubiquitination. Nat Chem Biol 8: 383-392, 2012.

26. Sackton KL, Dimova N, Zeng X, Tian W, Zhang M, Sackton TB, Meaders J, Pfaff KL, Sigoillot F, Yu H, et al: Synergistic blockade of mitotic exit by two chemical inhibitors of the APC/C. Nature 514: 646-649, 2014.

27. Das T, Roy KS, Chakrabarti T, Mukhopadhyay S and Roychoudhury S: Withaferin A modulates the Spindle assembly checkpoint by degradation of Mad2-Cdc20 complex in colorectal cancer cell lines. Biochem Pharmacol 91: 31-39, 2014.

28. Jiang J, Thyagarajan-Sahu A, Krchňák V, Jedinak A, Sandusky GE and Sliva D: NAHA, a novel hydroxamic acid-derivative, inhibits growth and angiogenesis of breast cancer in vitro and in vivo. PLoS One 7: e34283, 2012

29. Jiang J, Jedinak A and Sliva D: Ganodermanontriol (GDNT) exerts its effect on growth and invasiveness of breast cancer cells through the down-regulation of CDC20 and uPA. Biochem Biophys Res Commun 415: 325-329, 2011.

30. Nasr T, Bondock S and Youns M: Anticancer activity of new coumarin substituted hydrazide-hydrazone derivatives. Eur J Med Chem 76: 539-548, 2014.

31. Maugeri-Saccà M, Vigneri $\mathrm{P}$ and De Maria R: Cancer stem cells and chemosensitivity. Clin Cancer Res 17: 4942-4947, 2011.

32. Flahaut M, Meier R, Coulon A, Nardou KA, Niggli FK, Martinet D, Beckmann JS, Joseph JM, Mühlethaler-Mottet A and Gross N: The Wnt receptor FZD1 mediates chemoresistance in neuroblastoma through activation of the Wnt/beta-catenin pathway. Oncogene 28: 2245-2256, 2009.

33. Hadjihannas MV, Bernkopf DB, Brückner M and Behrens J: Cell cycle control of $\mathrm{Wnt} / \beta$-catenin signalling by conductin/axin2 through CDC20. EMBO Rep 13: 347-354, 2012.

34. Bisson I and Prowse DM: WNT signaling regulates self-renewal and differentiation of prostate cancer cells with stem cell characteristics. Cell Res 19: 683-697, 2009. 
35. Ni J, Cozzi P, Hao J, Duan W, Graham P, Kearsley J and Li Y: Cancer stem cells in prostate cancer chemoresistance. Curr Cancer Drug Targets 14: 225-240, 2014.

36. Song LN, Herrell R, Byers S, Shah S, Wilson EM and Gelmann EP: Beta-catenin binds to the activation function 2 region of the androgen receptor and modulates the effects of the $\mathrm{N}$-terminal domain and TIF2 on ligand-dependent transcription. Mol Cell Biol 23: 1674-1687, 2003.

37. Yang F, Li X, Sharma M, Sasaki CY, Longo DL, Lim B and Sun Z: Linking beta-catenin to androgen-signaling pathway. J Biol Chem 277: 11336-11344, 2002.
38. Yamada T, Takaoka AS, Naishiro Y, Hayashi R, Maruyama K, Maesawa C, Ochiai A and Hirohashi S: Transactivation of the multidrug resistance 1 gene by $\mathrm{T}$-cell factor $4 /$ beta-catenin complex in early colorectal carcinogenesis. Cancer Res 60: 4761-4766, 2000.

39. Gottesman MM, Fojo T and Bates SE: Multidrug resistance in cancer: Role of ATP-dependent transporters. Nat Rev Cancer 2: 48-58, 2002.

40. Kimura Y, Morita SY, Matsuo M and Ueda K: Mechanism of multidrug recognition by MDR1/ABCB1. Cancer Sci 98: 1303-1310, 2007. 